\title{
Low-Dose Fulvestrant
} Maintained Long-Term Complete Remission after Poor Response to Previous Endocrine Therapies in a Patient with Advanced Breast Cancer

\author{
H. Hawle $\quad$ D. Hess ${ }^{a} \quad$ A. Mueller ${ }^{a, c} \quad$ B. Thuerlimann ${ }^{b}$

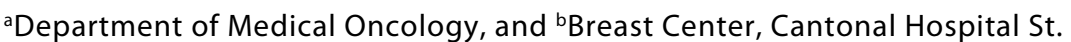 \\ Gallen, St. Gallen, and 'Department of Medical Oncology, Cantonal Hospital \\ Winterthur, Winterthur, Switzerland
}

\section{Key Words}

Advanced breast cancer - Sequential endocrine therapy · Fulvestrant - Pharmacokinetic profile $\cdot$ Long-term complete remission

\begin{abstract}
We report a case of long-term (9 years) response to 4th-line endocrine treatment with fulvestrant given for advanced breast cancer after no or poor response to prior endocrine therapies. Complete remission was achieved with full dose and maintained even after dose reduction due to unanticipated intensity of mucosal toxicity. Complete remission was temporarily lost after fulvestrant was tentatively withdrawn (63 months after treatment start), but was re-achieved after renewal of half-dose treatment and last reconfirmed 90 months after treatment start. The pharmacokinetic profile provides evidence to hypothesize a unique sensitivity to fulvestrant in this patient which might explain both: toxicity and extraordinary efficacy.
\end{abstract}

\section{Introduction}

Fulvestrant (Faslodex ${ }^{\circledR}$; AstraZeneca) is a novel steroidal estrogen receptor (ER) antagonist lacking agonist effects. By covalent binding to the ER, receptors are rapidly downregulated, resulting in a decrease of cellular ER levels and complete abrogation of estrogen-sensitive gene transcription [1]. The efficacy of fulvestrant in patients with tamoxifen-resistant disease $[2,3]$ and in patients progressing on aromatase inhibitors [35] has been confirmed, thus giving the opportunity to extend the overall period during 


\begin{tabular}{|c|c|c|c|}
\hline $\begin{array}{l}\text { Case Reports in } \\
\text { Oincaly }\end{array}$ & $\begin{array}{l}\text { Case Rep Oncol 2010;3:131-136 } \\
\text { D0I: } 10.1159 / 000313838\end{array}$ & Published online: April 29, 2010 & $\begin{array}{l}\text { @ } 2010 \text { S. Karger AG, Basel } \\
\text { ISSN 1662-6575 } \\
\text { www.karger.com/cro }\end{array}$ \\
\hline
\end{tabular}

which hormonal agents may be used in women with endocrine-responsive advanced breast cancer.

However, the most efficacious dosing regimen is an ongoing debate. Two recent clinical trials are focusing on fulvestrant high-dose regimens (500 mg monthly) to optimize fulvestrant treatment. The neoadjuvant NEWEST trial [6] showed significantly greater biological activity benefit with high-dose fulvestrant compared to the approved dose. The randomized, double-blind CONFIRM (Comparison of Faslodex in Recurrent or Metastatic Breast Cancer) trial presented recently [7] has shown a small but statistically significant increase in time to progression for fulvestrant $500 \mathrm{mg}$ compared with fulvestrant $250 \mathrm{mg}$, without increase of toxicity.

We report a case achieving long-term complete remission under fulvestrant introduced after no or poor response to prior endocrine therapies, in whom the most efficacious dosing regimen was below the approved dose.

\section{Case Report}

In January 1993, a 47-year-old, premenopausal woman was diagnosed with a left breast cancer (pT1c(m)pN0M0) after bilateral subcutaneous mastectomy for relapsing fibroadenomas. The tumor was ER-positive (90\%), PgR-positive (70\%) as evaluated by immunohistochemistry and had a low-level HER2-gene amplification ratio of 2.22 (positive $>2.20$ ) as assessed in 2007. CA 15-3 was normal. Axillary dissection was carried out followed by radiotherapy (50 Gy total dose), but no adjuvant endocrine therapy was given.

In January 1998, distant recurrence was diagnosed in soft tissue (ER-negative, PgR-positive by histological assessment), in bone, pleura and lung (lymphangiosis carcinomatosa). CA 15-3 was $99 \mathrm{kU} / \mathrm{l}$ (normal $\leq 27 \mathrm{kU} / \mathrm{l})$ (fig. 1). The patient was asymptomatic. Anastrozole was started as 1st-line endocrine treatment in a clinical trial, but discontinued after 3 months due to progression in pleura/lung and in the contralateral breast. CA 15-3 had further increased to $189 \mathrm{kU} / \mathrm{l}$ (fig. 1). Six cycles of chemotherapy with paclitaxel $\left(175 \mathrm{mg} / \mathrm{m}^{2}\right)$ and doxorubicin $\left(60 \mathrm{mg} / \mathrm{m}^{2}\right)$, every 21 days (EORTC 10961), were given, followed by monthly pamidronate for 8 months. Partial remission for 10 months was achieved with normalized chest X-ray and CA 15-3.

In June 1999, cancer progressed in the contralateral breast. She received 9 months of tamoxifen as 2nd-line endocrine treatment, which resulted in stable disease for 6 months prior to progression (CA 15-3 re-rising). Exemestane was started as 3rd-line endocrine treatment, but discontinued 14 days later due to severe allergic exanthema.

In March 2001, cytological assessment of a further progression in the contralateral breast revealed an ER-positive, PgR-negative tumor and fulvestrant (250 mg intramuscular, monthly) was initiated as 4thline endocrine treatment. As the drug had not yet been licensed in Switzerland at that time, fulvestrant was initially provided free of charge through a Named Patient Program (supported by AstraZeneca). CA 15-3 level dropped rapidly (fig. 1). Twelve months later complete remission was achieved (normal cervical/thoracic/abdominal computed tomography scan, disappearance of previous tracer uptake in bone scan).

However, the patient experienced painful oral and vaginal dryness with loss of libido, ulcerative stomato-pharyngitis and an extensive thrombophlebitis of the left arm requiring temporary treatment interruptions. Symptomatic treatment was given in different combinations, but mucosal dryness and inflammation became an ongoing problem diminishing her quality of life.

Therefore, in February 2004, we decided to continue fulvestrant at half dose (125 mg monthly). Mucosal symptoms improved; however, when fulvestrant was once administered in full dose by error, painful oral and vaginal mucositis reoccurred.

In June 2006, complete remission was reconfirmed and fulvestrant was tentatively stopped 63 months after the 1st injection. The patient recovered from mucosal toxicity. However, complete remission was lost shortly thereafter (CA 15-3 re-rising, small suspicious pleura effusion), but reachieved 10 months after renewal of fulvestrant (125 mg monthly) (fig. 1). 


\begin{tabular}{|c|c|c|c|}
\hline $\begin{array}{c}\text { Case Reports in } \\
\text { Onacily }\end{array}$ & $\begin{array}{l}\text { Case Rep Oncol 2010;3:131-136 } \\
\text { DOI: 10.1159/000313838 }\end{array}$ & Published online: April 29, 2010 & \begin{tabular}{|l} 
@ 2010 S. Karger AG, Basel \\
ISSN $1662-6575$ \\
www.karger.com/cro
\end{tabular} \\
\hline
\end{tabular}

In January 2008, we finally decided to determine the patient's fulvestrant plasma concentrations under the 125-mg dose by the high-performance liquid chromatography (HPLC) method in the standard lab for fulvestrant plasma sample analyses. The maximum concentration detected was even below the predicted level (table 1). At follow-up in September 2008, the patient reported oral and vaginal dryness tolerable under symptomatic treatment. Complete remission was reconfirmed 90 months after fulvestrant treatment start.

Thereafter, CA 15-3 ranged between upper normal limit (UNL) and $1.3 \times$ UNL, but so far progression of disease has not been confirmed on restaging. At the last follow-up in March 2010, the patient was doing well. Treatment will be continued.

\section{Discussion}

As observed in several clinical trials and case studies, some patients experience prolonged duration of response with fulvestrant treatment for endocrine-responsive advanced breast cancer $[3,8,9]$. To our knowledge, a 9-years response to 4 th-line endocrine treatment with fulvestrant has not been reported in the literature so far. This case is remarkable in several aspects: First, achievement of long-lasting complete remission (last reconfirmed 90 months after treatment start) is very rare, especially after no or poor response to prior anastrozole/tamoxifen, obviously both not predictive for the efficacy of fulvestrant in this patient. Second, reducing the dose of fulvestrant due to unanticipated intensity of mucosal toxicity maintained complete remission in this case. Third, the obvious need for continuing treatment is also remarkable.

We think it is important to alert oncologists to the fact that the prior response to an aromatase inhibitor does not appear to be predictive for the benefit of fulvestrant, an observation also made in a phase II trial investigating fulvestrant in patients with primary or acquired aromatase inhibitor-resistance [4].

Abram et al. presented a case with endocrine-responsive advanced breast cancer, which also appeared to respond better to fulvestrant than to prior endocrine therapies. They assumed that the intramuscular administration by a health care professional may have resulted in improved compliance [8]. We had no evidence of suboptimal compliance to oral medication in our patient.

A Belgian study found a greater activity of fulvestrant in tumors expressing both ER and PgR [10]. Other investigators found fulvestrant activity not being reduced in PgRnegative tumors [11]. In our case, hormone receptor status was ER-positive/PgR-negative when repeated prior to start of fulvestrant treatment, though the primary tumor was ERand PgR-positive. PgR expression within the tumor is known to be patchy and a sampling error might have led to the ER-positive, PgR-negative result in the immunocytochemical analysis of the fine needle aspiration material.

Tumors for which fulvestrant therapy might be particularly appropriate are those ERpositive tumors with HER2 overexpression assuming ligand-independent ER activation seems to be a key feature [11-13]. However, available data are conflicting. In our case, HER2 amplification with a ratio of 2.22 was low and unlikely to contribute to the superiority of fulvestrant compared to anastrozole and tamoxifen by the abovementioned mechanism.

Several large trials have shown that fulvestrant is well tolerated $[2,3,4,14]$. Our patient experienced unusually severe mucosal toxicity together with complete remission under the approved $250-\mathrm{mg}$ dose, but clearly less toxicity while maintaining complete remission under a 125-mg dose. Mucosal toxicity cannot be explained by the patient's medical 


\begin{tabular}{|c|c|c|c|}
\hline $\begin{array}{c}\text { Cose Reports in } \\
\text { Onacily }\end{array}$ & $\begin{array}{l}\text { Case Rep Oncol 2010;3:131-136 } \\
\text { Dol: } 10.1159 / 000313838\end{array}$ & Published online: April 29, 2010 & \begin{tabular}{|l} 
@ 2010 S. Karger AG, Basel \\
ISSN 1662-6575 \\
www.karger.com/cro
\end{tabular} \\
\hline
\end{tabular}

history. The pharmacokinetic profile excluded faster absorption or a variation in drug metabolism which theoretically could have contributed to the observed toxicity and efficacy (table 1). Her fulvestrant plasma concentrations were below the observed mean for a 250-mg dose [15] and, importantly, even below the predicted mean for a 125-mg dose.

We therefore hypothesize an extraordinary sensitivity, but not a metabolic phenomenon as a key factor in the observations made in this case. This might explain toxicity, efficacy and the need for continuing treatment.

This observation is of particular interest in the ongoing fulvestrant dosing debate: our case might serve as a basis for future strategies investigating individual dosing as a promising approach for optimizing fulvestrant treatment.

\section{Acknowledgements}

We thank Dr. Christian Oehlschlegel from the Institute of Pathology of the Cantonal Hospital St. Gallen, Switzerland, for reviewing the ER/PgR-status in the specimens and performing HER2-testing by FISH (PathVision ${ }^{\circledR}$ ) in the primary tumor retrospectively. We also wish to thank Dr. Justin Lindemann, AstaZeneca, Macclesfield, UK, for providing access to Eurofins Medinet Breda, The Netherlands, and facilitating the pharmacokinetic analysis.

\section{Conflict of Interest}

Dr. Hawle received honoraria from AstraZeneca for the preparation of this manuscript. Dr. Hess, Dr. Mueller and Dr. Thuerlimann reported no conflict of interest regarding this article.

Table 1. Patient's fulvestrant plasma concentrations at 125-mg dose (steady state)

\begin{tabular}{llllll}
\hline & Pre-dose trough & Day 8 peak & Day 15 & Day 22 & Day 29 \\
\hline Concentration, ng/ml & $3.44(3.6 \pm 0.6)^{\mathrm{a}}$ & $5.17(7.7 \pm 1.0)^{\mathrm{a}}$ & 4.10 & 4.22 & 3.04 \\
\hline
\end{tabular}

a Predicted fulvestrant concentrations at $125-\mathrm{mg}$ dose (steady state) at trough and at peak, AstraZeneca Data on File. Predictions are based upon a pharmacokinetic model used to describe a phase III breast cancer population [16]. 
Fig. 1. Tumor marker and given treatments since recurrence of disease. 1 Endocrine treatments and chemotherapy (anastrozole Jan98, chemotherapy Apr98, tamoxifen Jun99, exemestane Apr00). 2 Fulvestrant (half dose since Feb04). 3 Fulvestrant stopped. 4 Fulvestrant re-started (half dose).

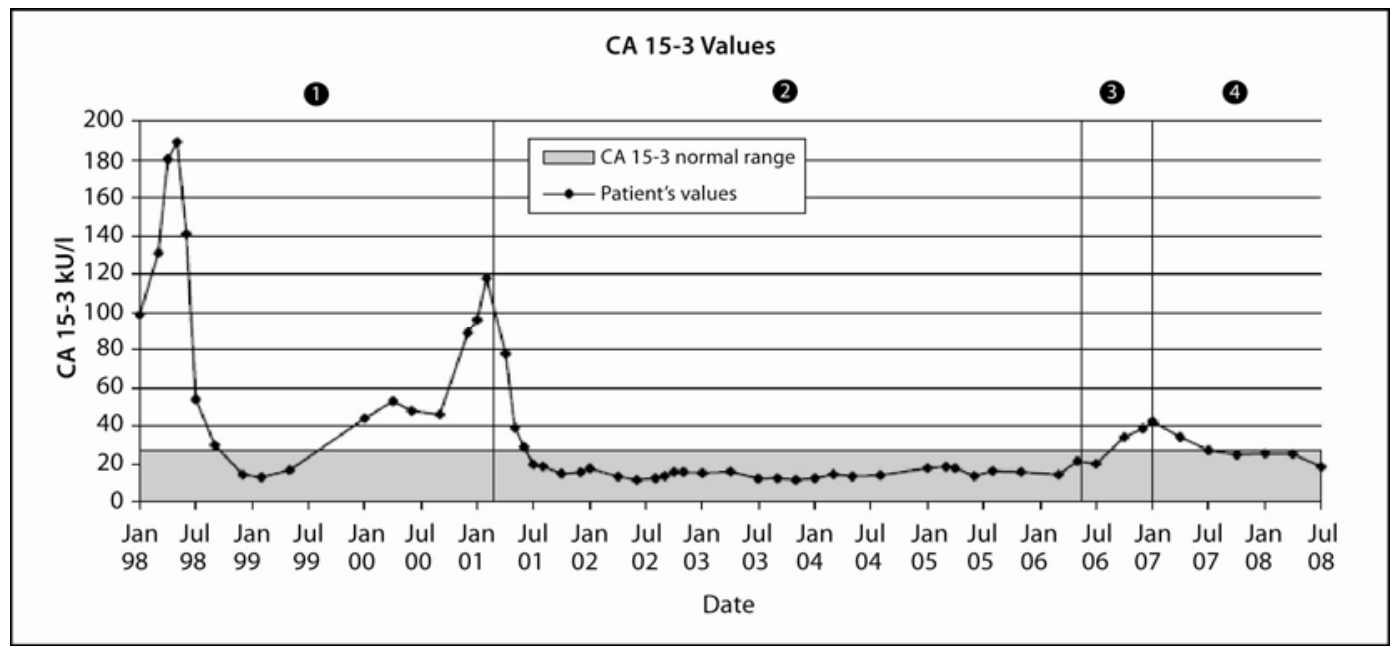




\begin{tabular}{|c|c|c|c|}
\hline $\begin{array}{l}\text { Case Reports in } \\
\text { Onatis }\end{array}$ & $\begin{array}{l}\text { Case Rep Oncol 2010;3:131-136 } \\
\text { D0I: 10.1159/000313838 }\end{array}$ & Published online: April 29, 2010 & $\begin{array}{l}\text { (c) } 2010 \text { S. Karger AG, Basel } \\
\text { ISSN } 1662-6575 \\
\text { www.karger.com/cro }\end{array}$ \\
\hline
\end{tabular}

\section{References}

1 Osborne CK, Wakeling A, Nicholson RI: Fulvestrant: an oestrogen receptor antagonist with a novel mechanism of action. Br J Cancer 2004;90(suppl):S2-S6.

-2 Robertson JFR, Osborne CK, Howell A, et al: Fulvestrant versus anastrozole for the treatment of advanced breast cancer in postmenopausal women - a prospective combined analysis of two multicenter trials. Cancer 2003;98:229-238.

-3 Ingle JN, Suman VJ, Rowland KM, et al: Fulvestrant in women with advanced breast cancer after progression on prior aromatase inhibitor therapy: North Central Cancer Treatment Group Trial N0032. J Clin Oncol 2006;24:1052-1056.

-4 Perey L, Paridaens R, Hawle H, et al: Clinical benefit of fulvestrant in postmenopausal women with advanced breast cancer and primary or acquired resistance to aromatase inhibitors: final results of phase II Swiss Group for Clinical Cancer Research Trial (SAKK 21/00). Ann Oncol 2007;18:64-69.

5 Chia S, Gradishar W, Mauriac L, et al: Double-blind, randomised placebo controlled trial of fulvestrant compared with exemestane after prior nonsteroidal aromatase inhibitor therapy in postmenopausal women with hormone receptorpositive, advanced breast cancer: results from EFECT. J Clin Oncol 2008;26:16641670.

-6 Kuter I, Hegg R, Singer CF, et al: Fulvestrant 500 mg versus 250 mg: first result from NEWEST, a randomized, phase II neoadjuvant trail in postmenopausal women with locally advanced, estrogen receptor-positive breast cancer. Breast Cancer Res Treat 2008;109:585-594 (abstract 23).

7 Di Leo A, Jerusalem G, Petruzelka L, et al: CONFIRM: a phase III, randomised, parallel-group trial comparing fulvestrant $250 \mathrm{mg}$ versus fulvestrant $500 \mathrm{mg}$ in postmenopausal women with estrogen receptor-positive advanced breast cancer. Cancer Res 2009;69(suppl):491s (abstract 25).

$\checkmark 8$ Abram P, Maass N, Rea D, et al: Case studies of fulvestrant ('Faslodex') in postmenopausal women with advanced breast cancer. Cancer Treat Rev 2005;31:S17-S25.

9 Jones SE, Pippen J, Webster A: A retrospective analysis of the portion of patients responding for $>1,1.5$ and 2 years in two phase III studies of fulvestrant versus anastrozole. Breast Cancer Res Treat 2004;88(suppl 1):S236 (abstract 6047).

10 Neven P, Paridaens R, Pelgrims G, et al: Fulvestrant (Faslodex ${ }^{\mathrm{TM}}$ ) in advanced breast cancer: clinical experience from a Belgian cooperative study. Breast Cancer Res Treat 2008;109:59-65.

11 Bartsch R, Wenzel C, Altorjai G, et al: Her2 and progesterone receptor status are not predictive of response to fulvestrant treatment. Clin Cancer Res 2007;13:4435-4439.

12 Normando N, Maio M, De Maio E, et al: Mechanisms of endocrine resistance and novel therapeutic strategies in breast cancer. Endocr Relat Cancer 2005;12:721747.

13 Robertson JFR, Steger GG, Neven P, et al: Activity of fulvestrant in Her2+ advanced breast cancer: Updated analysis. Abstract 184 presented at the American Society of Clinical Oncology Breast Cancer Symposium, September 57, 2008, Washington DC.

14 Vergote I, Abraham P: Fulvestrant, a new treatment option for advanced breast cancer: tolerability versus existing agents. Ann Oncol 2006;17:200-204.

15 Robertson JFR, Erikstein B, Osborne CK, et al: Pharmacokinetic profile of intramuscular fulvestrant in advanced breast cancer. Clin Pharmacokinet 2004;43:529-538.

16 McCormack P, Sapunar F: Pharmacokinetic profile of the fulvestrant loading dose regimen in postmenopausal women with hormone receptor-positive advanced breast cancer. Clin Breast Cancer 2008;8:347-351. 